Article

\title{
Emergency Healthcare Providers' Perceptions of Preparedness and Willingness to Work during Disasters and Public Health Emergencies
}

\author{
Mohammed Ali Salem Sultan ${ }^{1,2, *}$, Jarle Løwe Sørensen ${ }^{3} \mathbb{C}^{\text {, Eric Carlström }}{ }^{2,3}{ }^{\mathbb{C}}$, \\ Luc Mortelmans 4,5 and Amir Khorram-Manesh 6,7 (D) \\ 1 Directorate of Health Affairs in Najran, Najran 66255, Saudi Arabia \\ 2 Institute of Health and Care Sciences, Sahlgrenska Academy, Gothenburg University, \\ 41346 Gothenburg, Sweden; eric.carlstrom@gu.se \\ 3 USN School of Business, Campus Vestfold, University of South-Eastern Norway, 3603 Kongsberg, Norway; \\ jarle.sorensen@usn.no \\ 4 Center for Research and Education in Emergency Care, University of Leuven, 3000 Leuven, Belgium; \\ luc.mortelmans@zna.be \\ 5 Regedim, VUB, Brussels and dept of Emergency Medicine, ZNA, Stuivenberg, 2060 Antwerp, Belgium \\ 6 Institute of Clinical Sciences, Sahlgrenska Academy, Gothenburg University, 41390 Gothenburg, Sweden; \\ amir.khorram-manesh@surgery.gu.se \\ 7 Department of Research and Development, Swedish Armed Forces Centre for Defence Medicine, \\ 42676 Gothenburg, Sweden \\ * Correspondence: mohammed.sultan@gu.se; Tel.: +966-5661-23313
}

Received: 16 September 2020; Accepted: 26 October 2020; Published: 29 October 2020

\begin{abstract}
This study evaluates the perceptions of preparedness and willingness to work during disasters and public health emergencies among 213 healthcare workers at hospitals in the southern region of Saudi Arabia by using a quantitative survey (Fight or Flight). The results showed that participants' willingness to work unconditionally during disasters and emergencies varied based on the type of condition: natural disasters $(61.97 \%)$, seasonal influenza pandemic $(52.58 \%)$, smallpox pandemic (47.89\%), SARS/COVID-19 pandemic (43.56\%), special flu pandemic $(36.15 \%)$, mass shooting (37.56\%), chemical incident and bombing threats $(31.92 \%)$, biological events $(28.17 \%)$, Ebola outbreaks $(27.7 \%)$, and nuclear incident $(24.88 \%)$. A lack of confidence and the absence of safety assurance for healthcare workers and their family members were the most important reasons cited. The co-variation between age and education versus risk and danger by Spearman's rho confirmed a small negative correlation between education and danger at a 95\% level of significance, meaning that educated healthcare workers have less fear to work under dangerous events. Although the causes of unsuccessful management of disasters and emergencies may vary, individuals' characteristics, such as lack of confidence and emotional distractions because of uncertainty about the safety issues, may also play a significant role. Besides educational initiatives, other measures, which guarantee the safety of healthcare providers and their family members, should be established and implemented.
\end{abstract}

Keywords: confidence; disaster; emergency; healthcare; family member; preparedness

\section{Introduction}

A disaster is defined as "a serious disruption of functions in a community or a society resulting in widespread human, material, economic or environmental losses which exceed the ability of the affected community or society to cope using its resources" [1,2]. The Centre for Research on the Epidemiology of Disasters (CRED) reported that about 205 million people suffer from the negative outcomes of disasters 
each year [3]. These numbers of people continue to increase each year, with the increasing in the number of casualties and the severity of disasters such as volcanic eruption, earthquake, storm, flood, etc. [4]. The myriad of disasters and public health emergencies has compelled countries to rethink their security paradigms and preparedness to reduce the number of fatalities and the severity of destruction and disruptions [5].

Disaster preparedness should involve all levels of response systems [6]. The readiness to cope with a disaster encompasses all planning activities which take place at the state, institutional, and individual levels. Countries such as Sweden have maintained a societal security orientation in a bid to safeguard people and property and sustain resilience in planning and preparedness for unforeseen incidents and issues which may cause societal instability [7]. However, a number of stressors and an increased focus on danger may be demotivating factors for all agencies, but in particular healthcare professionals who work to help those in need in times of disasters and emergencies. Therefore, the perceived concerns of healthcare personnel should be highlighted and addressed.

While there are guidelines to assist practitioners in responding to emergency situations, the confidence of healthcare staff might be affected by factors such as individual characteristics and preparedness, training, family support, and communication $[7,8]$. Several studies have shown that various personal characteristics, such as age, experience, and education, have an effect on or are associated with how individuals perceive the importance of the risks [8,9]. Furthermore, certain factors such as the type of disaster, concern for family, concerns about personal safety, pet care needs and the lack of personal protective equipment (PPE) may influence the willingness (or lack of willingness) of staff to work during disasters [10]. For instance, some staff failed to return to their duties during the Bangkok flooding in 2011, as they were worried about the safety and locations of their relatives [11]. Although hospitals must be functional and appropriately staffed to receive the injured, hospital response plans seem to fail in considering the destruction of the hospital itself and the physical and emotional conditions of the healthcare workers during an incident. Thus, while healthcare workers are expected to be willing to respond to disasters, in reality, they might be reluctant to do so when the situation poses a threat to their safety [12].

The success of disaster plans is predicated on the willingness of the responders, whose perceptions of disaster preparedness are influenced by institutional and individual preparedness, experience of previous incidents, and family support $[13,14]$. A worker who feels physically unequipped and unsafe, or is not mentally prepared to respond to a disaster due to lack of experience may be reluctant to engage in risky attempts to save others, and to handle the challenges associated with emergency responses [10]. Moreover, as several studies have reported, a hospital's level of preparation also influences the confidence of the employees $[13,15,16]$. Consequently, while hospitals may be prepared, staff members such as nurses may not be confident in their ability to respond to a disaster.

It is, thus, not clear to what extent healthcare workers feel prepared or perceive the importance of staying prepared in the face of unprecedented disasters. A good understanding of disaster preparedness perceptions among healthcare workers can help considerably in the design and development of operational strategies, including training and exercises on how to respond to different types of disasters in both developed and developing countries [13].

The World Health Organization (WHO) stresses the need for healthcare institutions to prepare their workforce, including nurses and physicians, among others, to ensure preparedness and speed in dealing with different types of emergencies which may occur in the course of their practice [17]. The Kingdom of Saudi Arabia (KSA) has classified the levels of health service according to the Model of Care (MoC) description, which is divided into Activated people, Healthy communities, Virtual care, Primary care, Secondary care, Tertiary care, and Quaternary care. MoC describes a comprehensive care system for meeting health needs, which shifts the focus from curative care to preventive care. Systems of Care will operate less in hospitals and more in people's homes and communities [18]. Both governmental and private sectors offer healthcare. In the government sector, all levels of health care are provided free of charge [19]. The Ministry of Health (MOH) covers around $80 \%$ of the costs, 
and the remaining costs is covered by other agencies, such as the Armed Forces Military Services (AFMS), Health Services for Royal Commission in Jubal and Yanbua, the Saudi Arabian Oil Company (ARAMCO) Health Services, and others. The private sector provides all levels of health care to Saudi and non-Saudi for a fee [20].

The KSA has recorded a number of disasters such as flooding and fires. Although some measures to increase the degree of preparedness and responsiveness to various types of disasters, such as yearly exercises by many different agencies, have been suggested by the government, a recent fire at Jazan General Hospital revealed response deficiencies and a lack of disaster planning and preparedness [21]. Despite the collective approach in different exercises, a lack of vital skills and competencies may be associated with an inability among the KSA's healthcare workers to adequately plan and prepare for unpredicted events [22]. A recent study of this group showed that the majority of emergency staff at hospitals in the southern region of the KSA had good theoretical knowledge but insufficient practical knowledge. The study also showed that staffs with greater educational knowledge were more confident to act in emergencies and disaster events [23].

\section{Aim}

The aim of this study was to evaluate healthcare workers' perceptions of their preparedness and willingness to work during disasters and public health emergencies in the southern region of the KSA.

\section{Materials and Methods}

\subsection{Study Design}

This study employed a quantitative research design. A survey was used to generate a numeric representation of specific scenarios in healthcare. The behavioral characteristics, opinions, and attitudes of various stakeholders in healthcare were analyzed.

\subsection{Survey}

The study employed a validated English-language version of the (Fight or Flight) survey, provided by one of the authors (L.M.). The survey was developed and described in earlier studies [24,25]. The original version of the (Fight or Flight) survey was developed at the Center for Research and Education in Emergency Care (CREEC) of the University of Leuven, Belgium. A multi-scenario survey was developed, as at the time, literature was limited to pandemics. After a pilot study in one Belgian hospital, several disaster medicine experts from the Flemish Disaster Management course (CREEC, emergency nurses, and the military) validated a multi-centric version. This version does not allow studying the association between fear, stress, and emotion, but provides information necessary to establish such an association. It was modified for use in this study and provides a comprehensive analysis of the topic of study since it covers broad areas of disasters and public health emergencies. It works individually to assess several areas of healthcare and delves into in-depth information about the research. The survey is comprised of 60 items distributed between two sections: a demographic section consisting of 12 questions and a scenario section consisting of four scenarios (Willingness to go to work, Knowledge, Risk and Danger). Each scenario contains 12 dimensions, which can influence the working environment, presented as a question and illustrative example.

The willingness to work under a certain condition was marked as yes or no. The condition itself was marked in a predesignated field with 10 different choices: I will work during this incident if:

(a) I know my family is safe and taken care of;

(b) I am sure good communication lines with my family are available;

(c) My boss comes to work as well;

(d) I am trained to handle the situation;

(e) I get regular updates on the evolution of the incident; 
(f) Adequate PPE is provided;

(g) I get paid extra for it;

(h) I can get antivirals (e.g., Tamiflu) for free;

(i) I can get antidotes for free;

(j) I can get my vaccinations for free (Appendix A).

Furthermore, participants assessed their perceived knowledge in each scenario on a Likert scale by choosing between 1-10 points. One indicates the lowest and 10 the highest grade of perceived knowledge.

\subsection{Setting}

The study was conducted on Thursday 9 July 2020 at $10 \mathrm{MOH}$ hospitals $(n=10)$ in the Najran region, KSA. Najran is located in the southern part of the KSA, where the border is exposed to potential risk of disasters and armed conflict.

\subsection{Population and Sample}

The included participants were healthcare practitioners working in emergency departments (EDs), intensive care units (ICUs), and disaster teams/units, who were willing to participate, of all ages and gender groups. Workers who did not complete the survey, workers who were not present during the study period because of vacation or maternity leave, and personnel at the consultant or managerial level were excluded. All healthcare workers were informed about the study and its goals by the medical affairs administration in each of the hospitals, and informed consent was obtained. Workers were also informed that their participation was voluntary and that they could leave the study whenever they chose to. The participants were randomly chosen from the list of healthcare staff working in each ICU, ED, and disaster team/unit, thus avoiding the bias involved in choosing a specific group. The sample size was set at 250 healthcare practitioners based on the power calculation (Raosoft Inc., Seattle, WA, USA), assuming $4.5 \%$ precision with $50 \%$ prevalence and a population size of 508 with a $95 \%$ confidence interval specified limits.

\subsection{Data Collection and Processing}

The self-completion survey was presented to the participants through the SurveyMonkey website. All data were handled confidentially. Collected data were stored at the research center in each hospital. Healthcare practitioners answered the surveys on a specific research day to prevent response influence. The respondents were asked to provide accurate information. The information provided was subject only to research purposes, and the researcher could not disclose the respondents' identities at any time, no matter the circumstance.

\subsection{Ethical Approval}

An ethical committee certificate of approval for the study was obtained from the Institutional Review Board at the General Directorate of Health Affairs in the Najran region (IRB Log Number 2020-28 E; date of approval: 7 July 2020).

\subsection{Statistics}

The homogeneity of the items in the subscales of the Fight or Flight survey was analyzed by calculating Cronbach's alpha using the Statistical Package for the Social Sciences (SPSS) version 20 (IBM, Texas, USA). Cronbach's alpha was 0.927, showing high internal consistency; according to Brace et al. [26], this value is considered satisfactory. Other results are descriptively presented in actual numbers and percentages. 


\section{Results}

\subsection{Description of the Study Participants}

The total number of respondents was 334, but 121 did not complete the survey and were excluded from the study. Data were collected from the remaining 213 participants. The majority of the participants were females and over 50\% were nurses. About $53.52 \%$ were $25-34$ years old $(n=114)$. Some $63 \%$ $(n=136)$ had graduated from university. About $70.89 \%$ (151) of the participants were married, and $61.5 \%(n=131)$ had children. Among the 131 participants who had children, 90 participants indicated that their children lived with them. A total of 120 participants held leadership positions in their organizations, 175 participants (82.94\%) had regular contact with patients, and $128(60.38 \%)$ regularly worked in emergency units such as ICUs and EDs. Most of the participants had some kind of training (Table 1).

Table 1. Demographic data $(n=213)$

\begin{tabular}{|c|c|c|c|c|c|}
\hline Variable & $n$ & $\%$ & Variable & $n$ & $\%$ \\
\hline Position & & & Have children & & \\
\hline Supportive Services & 17 & 7.98 & Yes & 131 & 61.5 \\
\hline Nurse & 116 & 54.46 & No & 82 & 38.5 \\
\hline Administrator & 16 & 7.51 & Children living with them & & \\
\hline Physician & 47 & 22.07 & Yes & 90 & 42.65 \\
\hline $\begin{array}{c}\text { Paramedic/Emergency } \\
\text { Medical Technicians (EMT) }\end{array}$ & 17 & 7.98 & No & 121 & 57.35 \\
\hline Age by year & & & Function & & \\
\hline $20-24$ & 7 & 3.29 & Leader & 120 & 56.87 \\
\hline $25-34$ & 114 & 53.52 & Executor & 91 & 43.13 \\
\hline $35-44$ & 59 & 27.7 & Regular patient contact & & \\
\hline $45-54$ & 25 & 11.74 & Yes & 175 & 82.94 \\
\hline $55+$ & 8 & 3.76 & No & 36 & 17.06 \\
\hline Gender & & & Work at emergency units & & \\
\hline Male & 97 & 45.54 & Yes & 128 & 60.38 \\
\hline Female & 116 & 54.46 & No & 84 & 39.62 \\
\hline Level of education & & & Training & & \\
\hline Institute & 9 & 4.23 & Disaster Management & 171 & 82.61 \\
\hline College & 68 & 31.92 & Epidemic/pandemic & 85 & 41.06 \\
\hline University & 136 & 63.85 & Chemical incidents & 32 & 15.46 \\
\hline Marital status & & & Nuclear incidents & 9 & 4.35 \\
\hline Single & 62 & 29.11 & Mass casualty incidents & 60 & 28.99 \\
\hline Married & 151 & 70.89 & & & \\
\hline
\end{tabular}

\subsection{Willingness to Respond to Disasters and Emergencies}

The study participants' willingness to go to work during disasters and emergencies varied based on the type of condition (Table 2). There was no condition in which all of the participants were willing to work. Notably, the willingness of the participants to work unconditionally varied across conditions. More than $50 \%$ of participants were willing to work unconditionally when facing natural disasters such as flooding (61.97\%) or when dealing with a seasonal influenza pandemic (52.58\%). Over $40 \%$ of the respondents were willing to work unconditionally when facing smallpox (47.89\%) and SARS/COVID-19 (43.56\%). Up to $36.15 \%$ were willing to work unconditionally during a special flu pandemic. Ebola outbreaks (27.7\%) and biological incidents $(28.17 \%)$ such as anthrax were the least favorable incidents for working unconditionally. Of the various human-made disasters, a nuclear incident would result in the lowest number of participants willing to work unconditionally (24.88\%), followed by a chemical incident and bombing threat $(31.92 \%)$, a dirty bomb $(32.86 \%)$, and a mass shooting $(37.56 \%)$. 
Table 2. Willingness to go to work during various conditions $(n=213)$.

\begin{tabular}{|c|c|c|c|c|c|c|c|c|}
\hline \multirow[t]{2}{*}{$\begin{array}{c}\text { All Scenarios Affect Your Hospital } \\
\text { and Working Area }\end{array}$} & \multicolumn{2}{|c|}{ Yes, Unconditionally } & \multicolumn{2}{|c|}{$\begin{array}{l}\text { Yes, under Certain } \\
\text { Circumstances } a-j \#\end{array}$} & \multicolumn{2}{|c|}{$\begin{array}{l}\text { Have Serious Doubts, } \\
\text { Probably Not }\end{array}$} & \multicolumn{2}{|c|}{$\begin{array}{l}\text { I Will Certainly Not } \\
\text { Respond }\end{array}$} \\
\hline & $n$ & $\%$ & $n$ & $\%$ & $n$ & $\%$ & $n$ & $\%$ \\
\hline Natural disaster (e.g., flooding) & 132 & 61.97 & 63 & 29.58 & 9 & 4.23 & 9 & 4.23 \\
\hline Bombing (e.g., terrorist threat) & 68 & 31.92 & 89 & 41.78 & 38 & 17.84 & 18 & 8.45 \\
\hline Seasonal influenza pandemic & 112 & 52.58 & 83 & 38.97 & 14 & 6.57 & 4 & 1.88 \\
\hline Special flu pandemic (e.g., bird flu) & 77 & 36.15 & 106 & 49.77 & 20 & 9.39 & 10 & 4.69 \\
\hline SARS/COVID-19 & 93 & 43.66 & 97 & 45.54 & 16 & 7.51 & 7 & 3.29 \\
\hline Ebola outbreak & 59 & 27.70 & 56 & 26.29 & 71 & 33.33 & 27 & 12.68 \\
\hline Smallpox & 102 & 47.89 & 69 & 32.39 & 27 & 12.68 & 15 & 7.04 \\
\hline Chemical incident & 68 & 31.92 & 65 & 30.52 & 50 & 23.47 & 30 & 14.08 \\
\hline Biological incident (e.g., anthrax) & 60 & 28.17 & 54 & 25.35 & 74 & 34.74 & 25 & 11.74 \\
\hline Nuclear incident & 53 & 24.88 & 48 & 22.54 & 41 & 19.25 & 71 & 33.33 \\
\hline Dirty bomb & 70 & 32.86 & 83 & 38.97 & 37 & 17.37 & 23 & 10.80 \\
\hline Mass shooting (e.g., Paris) & 80 & 37.56 & 67 & 31.46 & 39 & 18.31 & 27 & 12.68 \\
\hline
\end{tabular}

Explanation of 'Under certain circumstances' a-j \#: (a) If I know my family is safe and taken care of; (b) If I am sure good communication lines with my family are available; (c) If my boss comes to work as well; (d) If I am trained to handle the situation; (e) If I get regular updates on the evolution of the incident; (f) If adequate PPE is provided; (g) If I get paid extra for it; (h) If I can get antivirals (e.g., Tamiflu) for free; (i) If I can get antidotes for free; (j) If I can get my vaccinations for free.

Some of the respondents expressed a willingness to work during disasters and emergencies under certain circumstances (Table 3). About $49.77 \%$ had demands for facing a special flu pandemic. Sixty-five of the 106 respondents demanded adequate PPE before they would go to work, 18 indicated that they would only go to work if they were properly trained, and eight indicated a willingness to go to work if their families were safe. In the same vein, $45.54 \%$ of the respondents indicated that they were willing to go to work in the case of a SARS/COVID-19 pandemic under certain circumstances. Adequate PPE was a requirement of 74 of the 97 who responded, followed by a consideration of the level of training. Additionally, $41.78 \%$ would consider going to work after a bombing under certain circumstances. Of these circumstances, the need to ensure that the respondent's family was safe and taken care of was considered the most pertinent, followed by the need for adequate training to deal with the situation. Seasonal influenza and a dirty bomb were the next two incidents in which respondents were most willing to go to work only under certain circumstances. For seasonal influenza, most respondents would consider going to work only if they were provided with PPE, were adequately trained to deal with the situation, and were assured that their families were safe.

Table 3. Willingness to go to work under certain circumstances (see explanations of a-j above).

\begin{tabular}{ccccccccccccc}
\hline $\begin{array}{c}\text { All Scenarios Affect Your Hospital } \\
\text { and Working Area }\end{array}$ & $\mathbf{a}$ & $\mathbf{b}$ & $\mathbf{c}$ & $\mathbf{d}$ & $\mathbf{e}$ & $\mathbf{f}$ & $\mathbf{g}$ & $\mathbf{h}$ & $\mathbf{i}$ & $\mathbf{j}$ & $\begin{array}{c}\text { Mean } \\
\text { Deviation }\end{array}$ \\
\hline Natural disaster $n=63$ & 26 & 5 & 2 & 22 & 3 & 2 & 1 & 0 & 1 & 1 & 2.97 & 2.130 \\
$\quad$ Bombing $n=89$ & 47 & 7 & 3 & 20 & 3 & 7 & 2 & 0 & 0 & 0 & 2.56 & 1.875 \\
Seasonal influenza pandemic $n=83$ & 9 & 2 & 1 & 13 & 1 & 50 & 2 & 0 & 2 & 3 & 5.25 & 2.118 \\
Special flu pandemic $n=106$ & 8 & 0 & 2 & 18 & 4 & 65 & 1 & 2 & 2 & 4 & 5.48 & 1.942 \\
SARS/COVID-19 $n=97$ & 4 & 0 & 2 & 11 & 3 & 74 & 1 & 1 & 0 & 1 & 5.56 & 1.354 \\
Ebola outbreak $n=56$ & 4 & 3 & 1 & 23 & 1 & 19 & 2 & 1 & 1 & 1 & 4.75 & 1.919 \\
$\quad$ Smallpox $n=69$ & 4 & 2 & 2 & 19 & 1 & 35 & 1 & 0 & 1 & 4 & 5.29 & 2.108 \\
Chemical incident $n=65$ & 13 & 0 & 1 & 25 & 2 & 21 & 2 & 0 & 1 & 0 & 4.23 & 1.951 \\
Biological incident $n=54$ & 3 & 1 & 2 & 24 & 2 & 17 & 2 & 1 & 0 & 2 & 4.87 & 1.914 \\
Nuclear incident $n=48$ & 14 & 0 & 0 & 19 & 4 & 9 & 1 & 0 & 1 & 0 & 3.67 & 2.077 \\
$\quad$ Dirty bomb $n=83$ & 39 & 2 & 3 & 29 & 2 & 8 & 0 & 0 & 0 & 0 & 2.72 & 1.783 \\
Mass shooting $n=67$ & 27 & 6 & 0 & 23 & 5 & 5 & 0 & 0 & 0 & 1 & 2.94 & 2.007 \\
\hline
\end{tabular}

Ensuring that their families were safe and taken care of and that they had an appropriate level of training were the special considerations under which most of the respondents were willing to go to work. Some practitioners were also willing to work under certain circumstances when faced with an Ebola outbreak, smallpox, and a biological incident. For an Ebola outbreak and a biological incident, the most important special considerations were the skills to handle the situation, closely followed by the availability of adequate PPE. When dealing with smallpox, the most important consideration was the availability of adequate PPE, followed by the knowledge to deal with the situation. 
Up to $30.52 \%$ of the respondents were willing to work under certain circumstances during a chemical incident. Of these circumstances, the knowledge required to deal with the incident was considered the most crucial, followed by the availability of adequate PPE and the knowledge that the respondent's family was safe. When facing a nuclear incident or a natural disaster, the most important considerations were whether the respondents were adequately trained to deal with the disaster and whether their families were safe.

A biological incident and an Ebola outbreak emerged as the two major disasters for which most respondents expressed serious doubt that they would go to work, $34.74 \%$ and 33.33\%, respectively. Another $23.47 \%$ of the respondents expressed serious doubt about attending work if there were a chemical incident, while only $4.23 \%$ expressed serious doubt that they would go to work if there was a natural disaster. Equally, there were few serious doubts about going to work when faced with a seasonal influenza pandemic, SARS/COVID-19, and a special flu pandemic. Some of the participants were sure that they would not go to work in case of disasters and emergencies. About $33.33 \%$ of the respondents were certain that they would not go to work if they were required to deal with a nuclear incident, $14.08 \%$ if there was a chemical incident, $12.68 \%$ if there was either an Ebola outbreak or a mass shooting, $1.88 \%$ if there was a seasonal influenza epidemic, and 3.29\% if there was a SARS/COVID-19 outbreak.

\subsection{Participant's Knowledge of Various Disasters}

Table 4 shows a self-rating of the participants' knowledge of various disasters and emergencies on a scale of 1 to 10 . The respondents rated themselves highly on their knowledge of how to deal with SARS/COVID-19, a seasonal influenza pandemic, and smallpox. On the other hand, the respondents gave themselves low ratings on their knowledge of bombing situations, an Ebola outbreak, a dirty bomb, a mass shooting, biological incidents, and terrorist threats.

Table 4. Participants' self-ratings of their knowledge on a Likert scale of 1 (no knowledge at all) to 10 (knowledge on specialist level).

\begin{tabular}{cccc}
\hline $\begin{array}{c}\text { All Scenarios Affect Your } \\
\text { Hospital and Working Area }\end{array}$ & Mean & Std. Deviation & $\begin{array}{c}\text { Confidence Interval } \\
\text { Lower Bound-Upper Bound }\end{array}$ \\
\hline Natural disaster & 5.59 & 2.281 & $5.28-5.90$ \\
Bombing & 4.89 & 2.598 & $4.54-5.24$ \\
Seasonal influenza pandemic & 6.77 & 2.298 & $6.46-7.08$ \\
Special flu pandemic & 5.71 & 2.422 & $5.39-6.04$ \\
SARS/COVID-19 & 7.80 & 2.172 & $7.51-8.10$ \\
Ebola outbreak & 4.64 & 2.719 & $4.27-5.01$ \\
Smallpox & 6.10 & 2.490 & $5.76-6.43$ \\
Chemical incident & 4.97 & 2.573 & $4.62-5.32$ \\
Biological incident & 4.38 & 2.711 & $4.02-4.75$ \\
Nuclear incident & 3.99 & 2.705 & $3.62-4.35$ \\
Dirty bomb & 4.97 & 2.507 & $4.63-5.31$ \\
Mass shooting & 5.23 & 2.413 & $4.91-5.56$ \\
\hline
\end{tabular}

\subsection{Risks and Dangers of Various Disasters}

The risk and associated danger of the SARS/COVID-19 pandemic occurring during participants' lifetimes were both at $80 \%$, followed by bombing and terrorist threats at $63 \%$ and $69 \%$, respectively. The likelihood of a seasonal influenza pandemic occurring during the study participants' lifetimes was viewed to be $62 \%$. A similar rating was given by participants' perceptions of the dangers posed by the disaster to society and the lives and health of individuals. These ratings indicate that seasonal influenza is considered a likely natural disaster with a significant impact on society. The likelihood of mass shootings, such as the Paris shooting, was considered 60\%. Its associated danger to society was considered $64 \%$ (Table 5). 
Table 5. Description of risk (0-100\% danger when it happens during respondent's lifetime) and danger (0-100\% danger disturbs the whole society and threatens population's lives and health).

\begin{tabular}{ccc}
\hline All Scenarios Affect Your & Risk & Danger \\
\cline { 2 - 3 } Hospital and Working Area & $\%$ & $\%$ \\
\hline Natural disaster & 58 & 64 \\
Bombing & 63 & 69 \\
Seasonal influenza pandemic & 62 & 62 \\
Special flu pandemic & 52 & 61 \\
SARS/COVID-19 & 80 & 80 \\
Ebola outbreak & 42 & 59 \\
Smallpox & 52 & 55 \\
Chemical incident & 48 & 59 \\
Biological incident & 40 & 55 \\
Nuclear incident & 41 & 64 \\
Dirty bomb & 47 & 64 \\
Mass shooting & 60 & 64 \\
\hline
\end{tabular}

The risks of a special flu pandemic and smallpox occurring were considered to be $52 \%$. However, a special flu pandemic was viewed as posing more danger than smallpox, namely, $61 \%$ compared to $55 \%$ for smallpox. It appears that the participants viewed smallpox as unlikely to have a significant impact on society compared to a special flu pandemic. A chemical incident was considered to have a $48 \%$ likelihood of occurring. However, its danger to society was considered high, at $59 \%$. In the same vein, the likelihood of a dirty bomb attack during the study participants' lifetimes was considered to be $47 \%$ and its danger $64 \%$ if it occurred. Equally, the risk of an Ebola outbreak was considered low at $42 \%$. Nevertheless, the dangers of such an outbreak on society were considered to be $59 \%$. A nuclear accident was considered unlikely to occur, with the respondents rating its risk as $41 \%$ and its danger at $64 \%$, making it the third most dangerous disaster in the views of respondents. The respondents viewed a biological incident as the least likely disaster to occur at $40 \%$. Nevertheless, they reported that it would pose a significant danger to society at $55 \%$.

Because age and education were presented as ranks, a non-parametric test, Spearman's rho was chosen to test the co-variation between age and education versus risk and danger. The test confirmed a small negative correlation between education and danger at a 95\% level of significance (Table 6).

Table 6. Ranks and statistics of Age and Education/Risk and Danger $(n=213)$.

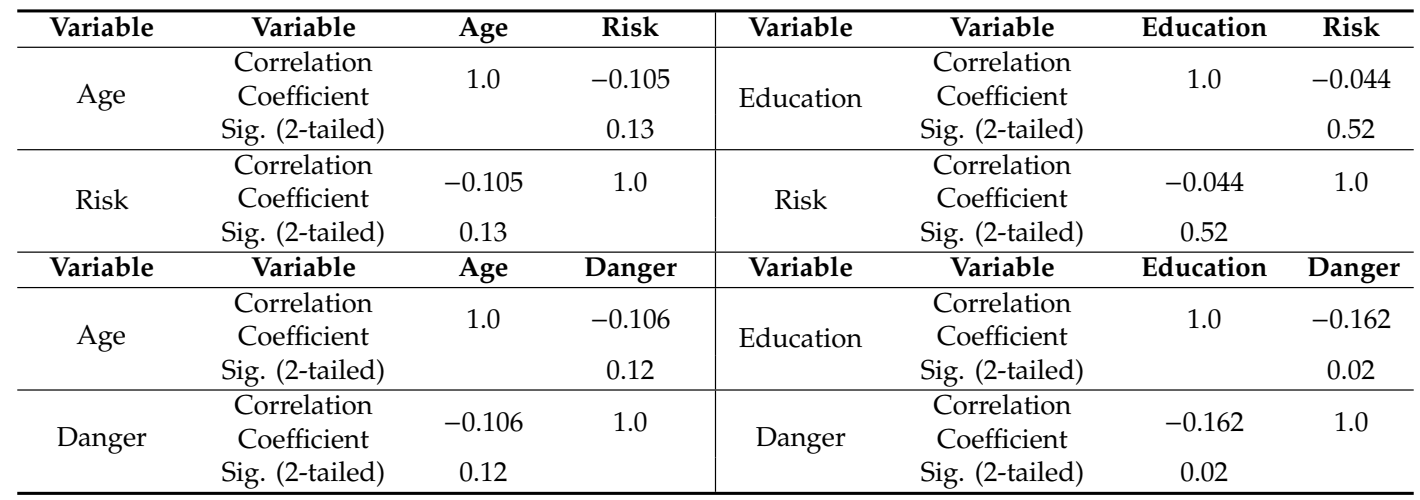

\section{Discussion}

In this study, we examined healthcare workers' perceptions of preparedness and willingness to work during disasters and emergencies in the southern region of the KSA. The primary reason for choosing this area for an evaluation was the continuous exposure of the region to both manmade and natural disasters, and earlier evaluation of their knowledge and competences [23]. The findings in 
this study indicate that although a high number of participants had training in disaster management, and were supposed to be prepared to respond to one, most of them were unwilling to provide care unconditionally except when dealing with natural disasters and a seasonal influenza pandemic.

Advanced education qualifications have been reported to play a crucial role in the willingness of healthcare workers to participate in disaster and emergency response [27]. In a previous study, examining the staff readiness in managing disasters in this region, the participants were shown to be theoretically well prepared, and particularly those with greater educational knowledge were more confident to act in emergencies and disasters [23]. Most of the participants in this study (63\%) also had a university degree and seemed to be well prepared. However, their enthusiasm for participation in various emergencies was limited. In fact, some of them could refuse to work during some events. Thus, being well prepared does not necessarily mean a willingness to act, and the willingness of staff to manage a condition seems to be significantly linked to their disease-related knowledge and experience $[8,28,29]$. These findings confirm the results of this study, which shows a selective willingness to take part in the management of some of the disasters or emergencies, such as natural disasters and seasonal flu or SARS. The staff seem to have less fear to handle these events and are more familiar with these conditions, maybe due to the KSA's disaster profile and the earlier epidemics [23].

Gee and Skovdal [30] argued that risk perception plays a role in determining the extent to which frontline health workers were willing to respond in a disaster or an emergency. The fear of personal safety and well-being of colleagues and family are all constraining factors, which distress and influence staff working attitudes during pandemics [31]. Nurses with experience in nursing patients infected with COVID-19 and nurses working in COVID-19 divisions had shown to have low job-retention intentions due to their emotional concerns and fear of becoming infected [32]. Chafee also reported that certain factors, such as the type of disaster, concern for family, pets, and personal safety have an impact on the willingness of staff to work during disasters [10]. These factors combined with special individual characteristics that influence individuals' risk perception result in an unwillingness to work during specific situations" [8,9]. Thus, frontline healthcare workers could become more confident in dealing with public health emergencies if they have the required knowledge and assurance of their families' safety [33].

While the number of healthcare workers keen to provide care during disasters and emergencies increases under certain circumstances, the findings in this study, presenting staff refusal to go to work in some types of disasters, are of real concern, and arguably, these findings need to be addressed. Anticipating that healthcare workers' knowledge, age, and other recorded characteristics could be an interesting determinant of their confidence and willingness to work, this study aimed to determine the association between some of these variables. Because age and education were presented as ranks, a non-parametric test, Spearman's rho, was chosen, and the co-variation between age and education versus risk and danger was tested. The test confirmed a small negative correlation between education and danger at a 95\% level of significance, i.e., those with more knowledge have less fear in working under unexpected incidents and are presumably more confident.

Several studies have shown that disaster preparedness training positively influences the responses of health staff to disasters and emergencies, and identifies the gap in knowledge and disaster preparedness $[29,34]$. Since knowledge and experience can promote the willingness to participate in the care of victims during hazardous incidents, it is necessary to provide disaster-specific training to healthcare workers to improve their disaster-related knowledge, increase their confidence, and reduce their fears. There should be more focus on multiagency and multi-professional training of all staff, particularly healthcare workers, irrespective of their positions and involvement in patient care, so that they are better equipped to respond collectively to disasters and emergencies.

This study identified challenges facing healthcare workers in the KSA in establishing a functional disaster response system. Lack of education and training might be one significant challenge to a functional disaster response system. However, safety issues (PPE and family safety) are crucial 
issues, which may threaten the effectiveness of a disaster response system, as most healthcare workers surveyed indicated that they would not respond unless they were sure that their families were safe.

The findings of this study suggest measures, which can be used to increase the competency of healthcare workers in the KSA in order to improve their efficiency and planning knowledge when dealing with emergencies and disasters. Disaster-specific education has been identified as a viable approach for improving the competency of healthcare workers in disaster management. Khorram-Manesh et al. [35] noted that the lack of standardization is a significant barrier to the effectiveness of disaster management courses. Thus, the KSA should consider establishing minimum standards and evaluation metrics to evaluate disaster management skills and training courses. The internet provides a platform for instructional delivery and should be considered to overcome the scarcity of time as a hindrance to the establishment of proper disaster management [36].

\section{Limitations}

This study has a number of limitations, which should be taken into consideration in future research. The survey was extensive; it contained 60 questions, which could be why 121 participants did not complete the survey. The sample consisted overwhelmingly of nurses and physicians working in ICUs, EDs, and disaster teams/units. The small number of included administrators, paramedics/emergency medical technicians, and supportive services workers was not representative of the entire hospital staff. Furthermore, data were collected in the Najran region in southern Saudi Arabia; thus, the results may not be generalizable to all parts of the country. Finally, the number of participants $(n=213)$ distributed in different professions and age groups results in a varying number of participants in each category, and thus, limits the generalization of the results to the population. Future studies should include a larger number of workers from diverse organizations to achieve representative and comprehensive findings.

\section{Conclusions}

The willingness of healthcare workers to respond is selective and depends on the type of disaster or emergency. This is an unexpected consideration for disaster and emergency planners. Among several factors that determine healthcare workers' willingness to work during disasters and public health emergencies, appropriate knowledge and skills to confidently manage an incident and the assurance of their families' safety are two decisive factors. Although we could only find a significant correlation between education and willingness to work during emergencies, previous reports have confirmed a significant correlation between education, age, and years of experience and the perception of hazards and fear and consequently willingness to work under threatening circumstances. While unsuccessful management of disasters and emergencies may be the result of organizational shortcomings and resource scarcity, healthcare workers' lack of knowledge, skills, and confidence and emotional distractions due to uncertainty about their own safety and that of their families may also play a significant role. Besides educational initiatives, which increase staff members' confidence through knowledge acquisition and skill improvement, other measures, which guarantee their families' safety and well-being during an emergency, should be established and implemented. Future contingency and disaster plans should include detailed information concerning all these important factors.

Author Contributions: Conceptualization: M.A.S.S., L.M. and A.K.-M.; data curation, M.A.S.S.; formal analysis, M.A.S.S., A.K.-M., E.C. and J.L.S.; investigation: M.A.S.S.; methodology, M.A.S.S., E.C., L.M. and A.K.-M.; project administration: M.A.-S.; resources: M.A.-S.; supervision, A.K.-M.; validation, E.C., J.L.S. and L.M. writing—original draft: M.A.S.S.; writing—review and editing, E.C., J.L.S., L.M. and A.K.-M. All authors have read and agreed to the published version of the manuscript.

Funding: This research received no external funding.

Acknowledgments: We would like to thank Hadi J Al Sulayyim for his cooperation in analyzing the data.

Conflicts of Interest: The authors declare no conflict of interest. 


\section{Appendix A}

Fight or Flight questionnaire/ part one

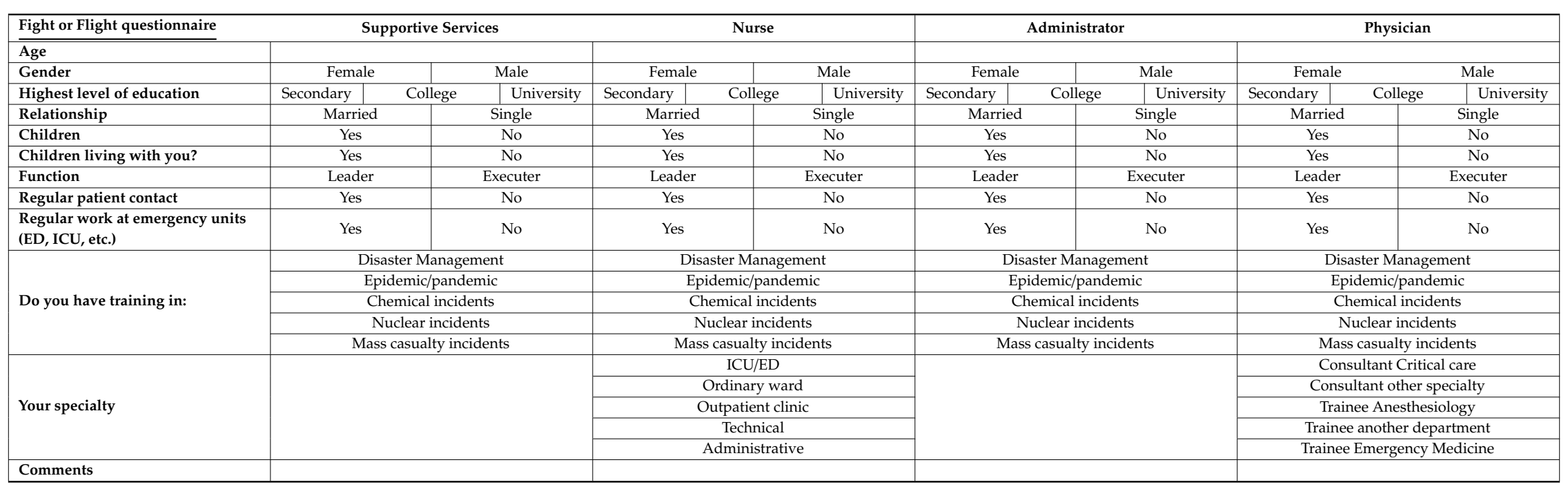




\section{Fight or Flight questionnaire/ part two}

1. Evaluation of scenarios

\begin{tabular}{|c|c|c|c|c|c|c|c|}
\hline \multirow{2}{*}{$\begin{array}{l}\text { Scenarios } \\
\text { All scenarios affecting your hospital and working area }\end{array}$} & \multicolumn{4}{|c|}{ Do you go to work? } & \multirow{2}{*}{$\begin{array}{c}\text { Knowledge } \\
\text { My knowledge on } \\
\text { the scenario; } 1-10 \\
\text { (10 is highest) }\end{array}$} & \multirow{2}{*}{$\begin{array}{c}\text { Risk } \\
\text { The risk for this } \\
\text { incident to happen } \\
\text { is } 0-100 \%\end{array}$} & \multirow{2}{*}{$\begin{array}{c}\text { Danger } \\
\text { The danger of this } \\
\text { situation is } 0-100 \%\end{array}$} \\
\hline & $\begin{array}{c}\text { Yes, } \\
\text { unconditionally }\end{array}$ & $\begin{array}{l}\text { Yes, under certain } \\
\text { circumstances } a-j \#\end{array}$ & $\begin{array}{l}\text { I have serious doubts, } \\
\text { probably not }\end{array}$ & $\begin{array}{l}\text { I will certainly not } \\
\text { respond }\end{array}$ & & & \\
\hline \multicolumn{8}{|l|}{ Natural disaster (e.g., flooding) } \\
\hline \multirow{2}{*}{\multicolumn{8}{|c|}{$\begin{array}{l}\text { Bombing (e.g., terrorist threat) } \\
\text { Seasonal influenza pandemic }\end{array}$}} \\
\hline \multirow{2}{*}{\multicolumn{8}{|c|}{$\begin{array}{l}\text { Seasonal influenza pandemic } \\
\text { Spiacl }\end{array}$}} \\
\hline & & & & & & & \\
\hline \multicolumn{8}{|l|}{ SARS/COVID-19 } \\
\hline \multirow{2}{*}{\multicolumn{8}{|c|}{$\begin{array}{l}\text { Ebola outbreak } \\
\text { Smallpox }\end{array}$}} \\
\hline & & \multicolumn{6}{|c|}{ Smallpox } \\
\hline \multicolumn{8}{|l|}{ Chemical incident } \\
\hline \multicolumn{8}{|l|}{ Biological incident (e.g., anthrax) } \\
\hline \multirow{2}{*}{\multicolumn{8}{|c|}{ Nuclear incident }} \\
\hline Dirty bomb & & & & & & & \\
\hline Mass shooting (e.g., Paris) & & & & & & & \\
\hline
\end{tabular}

2. \# If you answered "Under certain circumstances" then what of the below can make you go to work? Please insert one or more options of below a-j under the heading "under certain circumstances"

a. If I know my family is safe and taken care of;

b. I If I am sure good communication lines with my family are available;

c. If my boss comes to work as well;

d. If I am trained to handle the situation;

e. If I get regular updates on the evolution of the incident;

f. If adequate personal protective equipment (PPE) is provided;

g. If I get paid extra for it;

h. If I can get antivirals (e.g., Tamiflu) for free;

i. If I can get antidotes for free;

j. If I can get my vaccinations for free.

\section{Other comments}




\section{References}

1. Alzahrani, F.; Yiannis, K. Emergency nurse disaster preparedness during mass gatherings: A cross-sectional survey of emergency nurses' perceptions in hospitals in Mecca, Saudi Arabia. BMJ Open 2017, 7, e013563. [CrossRef] [PubMed]

2. Walczyszyn, M.; Patel, S.; Oron, M.; Mina, B.A. Perceptions of hospital medical personnel on disaster preparedness. F1000Research 2016, 5, 1938. [CrossRef]

3. The Centre for Research on the Epidemiology of Disasters (CRED). The Human Cost of Weather-Related Disasters, 1995-2015; United Nations: Geneva, Switzerland, 2015.

4. Banajah, S. Critiquing Disaster Nursing Competencies in Relation to International Standards Writhing Resilient Health Care System in Saudi Arabia. J. US China Public Adm. 2018, 15, 181-197. [CrossRef]

5. Paton, D.; Buergelt, P.T. Risk, Transformation and Adaptation: Ideas for Reframing Approaches to Disaster Risk Reduction. Int. J. Environ. Res. Public Health 2019, 16, 2594. [CrossRef]

6. Ogedegbe, C.; Nyirenda, T.; DelMoro, G.; Yamin, E.; Feldman, J. Health care workers and disaster preparedness: Barriers to and facilitators of willingness to respond. Int. J. Emerg. Med. 2012, 5, 29. [CrossRef]

7. Lindberg, H.; Sundelius, B. Whole-of-society disaster resilience: The Swedish way. In The McGraw-Hill Homeland Security Handbook; McGraw-Hill: New York, NY, USA, 2013; pp. 1295-1319.

8. Diakakis, M.; Damigos, D.G.; Kallioras, A. Identification of Patterns and Influential Factors on Civil Protection Personnel Opinions and Views on Different Aspects of Flood Risk Management: The Case of Greece. Sustainability 2020, 12, 5585. [CrossRef]

9. Ahayalimudin, N.; Osman, N.N.S. Disaster management: Emergency nursing and medical personnel's knowledge, attitude and practices of the East Coast region hospitals of Malaysia. Australas. Emerg. Nurs. J. 2016, 19, 203-209. [CrossRef]

10. Chaffee, M. Willingness of Health Care Personnel to Work in a Disaster: An Integrative Review of the Literature. Disaster Med. Public Health Prep. 2009, 3, 42-56. [CrossRef] [PubMed]

11. Khorram-Manesh, A.; Angthong, C.; Pangma, A.; Sulannakarn, S.; Burivong, R.; Jarayabhand, R.; Örtenwall, P. Hospital Evacuation; Learning from the Past? Flooding of Bangkok 2011. Br. J. Med. Med. Res. 2014, 4, 395-415. [CrossRef]

12. Smith, E.; Morgans, A.; Qureshi, K.; Burkle, F.; Archer, F. Paramedics' perceptions of risk and willingness to work during disasters. Aust. J. Emerg. Manag. 2009, 24, 21-27.

13. O'Sullivan, T.L.; Dow, D.; Turner, M.C.; Lemyre, L.; Corneil, W.; Krewski, D.; Phillips, K.P.; Amaratunga, C.A. Disaster and emergency management: Canadian nurses' perceptions of preparedness on hospital front lines. Prehosp. Disaster Med. 2008, 23, s11-s19. [CrossRef] [PubMed]

14. Lim, G.H.; Lim, B.L.; Vasu, A. Survey of Factors Affecting Health Care Workers' Perception Towards Institutional and Individual Disaster Preparedness. Prehosp. Disaster Med. 2013, 28, 353-358. [CrossRef]

15. Baack, S.; Alfred, D. Nurses' Preparedness and Perceived Competence in Managing Disasters. J. Nurs. Sch. 2013, 45, 281-287. [CrossRef] [PubMed]

16. Whetzel, E.; Walker-Cillo, G.; Chan, G.K.; Trivett, J. Emergency Nurse Perceptions of Individual and Facility Emergency Preparedness. J. Emerg. Nurs. 2013, 39, 46-52. [CrossRef]

17. World Health Organization; International Council of Nurses (ICN). ICN Framework of Disaster Nursing Competencies; World Health Organization: Geneva, Switzerland; International Council of Nurses (ICN): Geneva, Switzerland, 2009; p. 84.

18. Ministry of Health. Introductory Guide to National Transformation Programs in the Health Sector. 2018. Available online: https://www.moh.gov.sa/Ministry/MediaCenter/Publications/Documents/2018-11-01-010. pdf (accessed on 2 October 2020).

19. Almalki, M.; Fitzgerald, G.; Clark, M. The nursing profession in Saudi Arabia: An overview. Int. Nurs. Rev. 2011, 58, 304-311. [CrossRef] [PubMed]

20. Mufti, M.H. Healthcare Development Strategies in the Kingdom of Saudi Arabia; Springer Science \& Business Media: New York, NY, USA, 2000; pp. 64-66.

21. Bajow, N.; Djalali, A.; Ingrassia, P.L.; Ragazzoni, L.; Ageely, H.; Bani, I.; Della Corte, F. Evaluation of a new community-based curriculum in disaster medicine for undergraduates. BMC Med. Educ. 2016, 16, 225. [CrossRef] 
22. Al Thobaity, A.; Plummer, V.; Innes, K.; Copnell, B. Perceptions of knowledge of disaster management among military and civilian nurses in Saudi Arabia. Australas. Emerg. Nurs. J. 2015, 18, 156-164. [CrossRef] [PubMed]

23. Sultan, M.A.S.; Khorram-Manesh, A.; Carlström, E.; Sørensen, J.L.; Al Sulayyim, H.J.; Taube, F. Nurses' Readiness for Emergencies and Public Health Challenges-The Case of Saudi Arabia. Sustainability 2020, 12, 7874. [CrossRef]

24. Dewolf, P.; Mortelmans, L.J.M.; Luyts, J.; De Cauwer, H.G.; Sabbe, M. Fight or flight: Will nurses and ambulance personnel go to work in disaster situations? Acta Clin. Belg. 2010, 65, 146.

25. Hendrickx, C.; Van Turnhout, P.; Mortelmans, L.; Sabbe, M.; Peremans, L. Willingness to Work of Hospital Staff in Disasters: A Pilot Study in Belgian Hospitals. Prehosp. Disaster Med. 2017, 32, 21. [CrossRef]

26. Brace, N.; Kemp, R.; Snelgar, R. SPSS for Psychologists: A Guide to Data Analysis Using SPSS for Windows, 3rd ed.; Lawrence Erlbaum Associates Publishers: Mahwah, NJ, USA, 2006.

27. Al-Hunaishi, W.; Hoe, V.C.; Chinna, K. Factors associated with healthcare workers willingness to participate in disasters: A cross-sectional study in Sana'a, Yemen. BMJ Open 2019, 9, e030547. [CrossRef] [PubMed]

28. Cotanda, C.P.; Martínez, M.R.; De La Maza, V.T.S.; Cubells, C.L. Impact of a disaster preparedness training programme on health staff. An. Pediatría 2016, 85, 149-154. [CrossRef]

29. Patel, R.; Wattamwar, K.; Kanduri, J.; Nahass, M.; Yoon, J.; Oh, J.; Shukla, P.; Lacy, C.R. Health Care Student Knowledge and Willingness to Work in Infectious Disease Outbreaks. Disaster Med. Public Health Prep. 2017, 11, 694-700. [CrossRef] [PubMed]

30. Gee, S.; Skovdal, M. The role of risk perception in willingness to respond to the 2014-2016 West African Ebola outbreak: A qualitative study of international health care workers. Glob. Health Res. Policy 2017, 2, 21. [CrossRef] [PubMed]

31. Khalid, I.; Khalid, T.J.; Qabajah, M.R.; Barnard, A.G.; Qushmaq, I.A. Healthcare Workers Emotions, Perceived Stressors and Coping Strategies During a MERS-CoV Outbreak. Clin. Med. Res. 2016, 14, 7-14. [CrossRef] [PubMed]

32. Kim, Y.-J.; Lee, S.-Y.; Cho, J.-H. A Study on the Job Retention Intention of Nurses Based on Social Support in the COVID-19 Situation. Sustainability 2020, 12, 7276. [CrossRef]

33. Hope, K. Willingness of frontline health care workers to work during a public health emergency. Aust. J. Emerg. Manag. 2010, 25, 39-47.

34. Veenema, T.G.; Griffin, A.; Gable, A.R.; MacIntyre, L.; Simons, R.N.; Couig, M.P.; Walsh, J.J.; Lavin, R.P.; Dobalian, A.; Larson, E. Nurses as Leaders in Disaster Preparedness and Response-A Call to Action. J. Nurs. Sch. 2016, 48, 187-200. [CrossRef]

35. Khorram-Manesh, A.; Ashkenazi, M.; Djalali, A.; Ingrassia, P.L.; Friedl, T.; Von Armin, G.; Lupesco, O.; Kaptan, K.; Arculeo, C.; Hreckovski, B.; et al. Education in Disaster Management and Emergencies: Defining a New European Course. Disaster Med. Public Health Prep. 2015, 9, 245-255. [CrossRef]

36. Naser, W.N.; Saleem, H.B. Emergency and disaster management training; knowledge and attitude of Yemeni health professionals-A cross-sectional study. BMC Emerg. Med. 2018, 18, 1-12. [CrossRef]

Publisher's Note: MDPI stays neutral with regard to jurisdictional claims in published maps and institutional affiliations.

(C) 2020 by the authors. Licensee MDPI, Basel, Switzerland. This article is an open access article distributed under the terms and conditions of the Creative Commons Attribution (CC BY) license (http://creativecommons.org/licenses/by/4.0/). 